\title{
A Cross-Border Acceleration Program: The Case of Slovenia and Italy
}

\author{
TINA BRATKOVIČ KREGAR \\ University of Primorska, Slovenia \\ tina.bratkovic.kregar@fm-kp.si \\ MITJA RUZZIER \\ University of Primorska, Slovenia \\ mitja.ruzzier@fm-kp.si
}

Startups and SmES are considered to be key players in the economic development of nations. That means it is necessary to establish an ecosystem that will allow these firms to develop and grow. Our paper deals with the role of regional innovation ecosystems in the process of developing and nurturing these companies. In particular, we investigate the role of a cross-border collaboration in establishing a regional innovation ecosystem that goes beyond borders, and provide evidence of a successful cross-border collaboration between Italy and Slovenia. Based on primary and secondary data collection, an integrated model of a cross-border acceleration program was developed. Our findings have important implications for cross-border collaboration in the area of establishing cross-border accelerator programs, and represent an example of best practice in this filed. In the future consideration of support and encouragement of innovation ecosystems, crossborder collaboration should be seen fundamental for efficient technology and knowledge transfer from research institutions to companies.

Key words: entrepreneurship, innovation ecosystem, startup, accelerator, cross-border collaboration

(c))BY-SA https://doi.org/10.26493/1854-4231.15.241-264

\section{Introduction}

Successful startups and small and medium enterprises (SMES) have the ability to create new jobs and contribute to the economic welfare. Especially startups are considered to be a key player in the economic development. In order to support the development and growth of startups and SMEs, a suitable ecosystem needs to be developed to provide external support and appropriate environmental conditions for their survival and growth (Ojaghi, Mohammadi, and 
Yazdani, 2019, Tripathi et al. 2019b). Among the various actors and types of support, accelerator programs have been identified as an important part of the entrepreneurial ecosystem (Cohen et al. 2019).

The region's business ecosystem may determine the success of firm development. A worldwide example for a region that is best known for its successful startup creation is the Silicon Valley in North California (USA) (Tripathi et al. 2019b). It is acknowledged that the main reason for the success of the Silicon Valley is the spirit of cooperation. The relationships established among its network members facilitate the exchange of resources and enable innovative companies to grow and become highly profitable (Amadeo 2020).

Based on the awareness about the importance of proximity to suppliers, customers and technology to achieve a competitive advantage, the idea of developing a suitable innovation ecosystem in the ItalianSlovenian cross-border region was born. It was called the Crossborder Acceleration Bridge for entrepreneurs - САВ. The purpose of this program was to empower local resources, become a facilitator in the startup phase, support Smes in the process of internationalization and encourage the exchange between industry and researchers. The main questions investigated during the project were related to the needs of companies in the Italian-Slovenian cross-border region, like what do new firms actually need to survive and grow and what do SMEs need in order to go international. Around these two key questions the integrated model of a cross-border acceleration program was jointly design by Italian and Slovenian partners.

The aim of the program was to provide a new cross-border service that will become a fundamental part of the innovation ecosystem of Alpe-Adria. By establishing relationships among research institutions, universities, companies and organizations for entrepreneurship support from three regions (Friuli Venezia Giulia (Italy), Veneto (Italy) and Slovenia), one of the main outputs would be a consolidated cross-border network that will provide innovative services to foster entrepreneurship in the cross-border area and also beyond it. In fact, past research has shown that language and legislative issues might be barriers for practical cross-border cooperation, but on the other hand differences in culture and technology may facilitate the cross-border knowledge transfer (Makkonen et al. 2018).

The main objectives of our study are to present the role and importance of innovation ecosystems and accelerators in the process of firm development and technology transfer from research centres to business, and to present the case study of the cross-border collaboration between Slovenia and Italy in co-establishing a cross-border 
acceleration program. In order to achieve our goals, we developed two research questions:

1. How do accelerators contribute to the development and growth of startups and SMEs?

2. What are the key elements of a cross-border acceleration program based on the specific needs of Slovenian and Italian companies?

To answer these two questions, a structured literature review on startups and acceleration programs was conducted, an analysis of the Smart Specialization Strategy (s3) of Friuli Venezia Giulia, Veneto and Slovenia was performed to identify the best opportunity areas of cross-border collaboration between the two countries, and a comparative analysis of entrepreneurship support systems in the Italian-Slovenian cross-border region was conducted.

\section{Theoretical Background}

The economic growth of a country heavily depends on the ability of its companies to develop innovative products and services (Fritsch and Noseleit 2013, Tripathi et al. 2019b). In developing innovative products, startups have a key role, since their primary cause of birth is their innovation capability (Ojaghi, Mohammadi, and Yazdani 2019). They have the ability to disrupt an existing market and scale themselves into unicorns (Tripathi et al. 2019a). Today, due to the increased openness in innovation and technology, the entry barriers for new startups are lower than in past (Ojaghi, Mohammadi, and Yazdani 2019).

Startups can be defined as temporary organizations in search for the right, repeatable and scalable business model or as organizations with the aim of creating new products under uncertain circumstances with limited experiences and inadequate resources. They cannot be treated just as smaller versions of big companies (Blank and Dorf 2012; Clarysse and Bruneel 2007; Ojaghi, Mohammadi, and Yazdani 2019, Ries 2011; Tripathi et al. 2019b). Startups are seen as major source of innovation, since they constantly seek for new technologies to develop new products and redesign new business models (Kohler 2016). They represent an effective mechanism for creating new jobs in developing countries (Humala 2015). Statistical data show that annually startups create an average of 3 million new jobs only in the United States.

Therefore, the policy makers responsible for the employment growth should definitely give a special emphasis to this type of com-

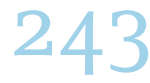


panies and develop measures that contribute to their development (Kane 2010).

Startups might be seen as the key drivers of innovativeness and growth in the nowadays society, but at the same time they are extremely vulnerable, and therefore require special external support. Startups are new-born companies that are exposed to numerous challenges, like for example the shortage of resources (Ojaghi, Mohammadi, and Yazdani 2019). They are foreigners on the market and therefore they lack reputation and market knowledge (Lichtenthaler and Ernst 2008). Research shows that most early-stage startups fail within two years from their establishment, mainly because they fail to achieve a good problem-solution fit and because they fail to learn during the process of customer and product development. Hence, in order to increase the survival rate of startups, a suitable innovation ecosystem that provides them with adequate support from product idea development until market entrance is needed (Tripathi et al. 2019a). The aim of every startup is to become a steady and independent company.

\section{INNOVATION ECOSYSTEM}

Past research has confirmed that in order to foster the development of startups, an adequate ecosystem must be developed around these firms (Tripathi et al. 2019a). During the literature review on this topic, we came across different naming of ecosystems, like for example startup ecosystem, business ecosystem, innovation ecosystem and entrepreneurial/business ecosystem. The differences are mainly due to different points of view from which an ecosystem is considered. For example, the innovation ecosystem is focused on innovation, while the business ecosystem is usually focused on a product, customer or an industry (Ojaghi, Mohammadi, and Yazdani 2019). The innovation ecosystem is often understood as a synonymous with the business ecosystem, since both are focused on creating a collaborative network that aims at innovation by adopting a systematic approach (Fenga et al. 2019). Some authors believe that there should be a distinction between an entrepreneurial ecosystem and startup ecosystem, since promoting entrepreneurship and startups are two different things. Though, they are inter-reliant (Tripathi et al. 2019b).

Cohen (2006) describes the entrepreneurial ecosystem as a geographic region, in which interdependent actors mutually interact to create new ventures over time (like startups, but not only). These interdependent actors may have impact on the formation and growth 